\title{
Getting stuck or choosing to stay? Neutrophil transit times in the lung in acute inflammation and COPD
}

\author{
Elizabeth Sapey, ${ }^{1}{ }^{1}$ Robert A Stockley ${ }^{2}$
}

The neutrophil is generally recognised as a key cellular mediator in the pathophysiology of chronic obstructive pulmonary disease (COPD). This is based on the propensity for the cell to release proinflammatory mediators including superoxide radicals and importantly serine proteinases. These products have been shown to replicate many of the pathological changes typical of COPD in cell-based and animal models ${ }^{1}$ and have significant potential for bystander tissue damage, especially when the neutrophil is primed or activated and degranulates more readily. ${ }^{2}$ Further, studies have consistently shown increased numbers of neutrophils, neutrophil-associated cytokines and neutrophil chemoattractants in COPD airway fluids (be they collected as spontaneous $^{3}$ or induced sputum ${ }^{4}$ or as bronchoalveolar lavage ${ }^{5}$ ) and the numbers of neutrophils and their products correlate with disease severity/activity, as determined by the degree of airway obstruction, decline in $\mathrm{FEV}_{1}$ (Forced Expiratory Volume in 1 Second) or severity of emphysema present. ${ }^{6}$ Also, neutrophilia in COPD lung secretions is seen regardless of the clinical phenotype; although some phenotypes are associated with a greater burden of neutrophilic inflammation or a reduced capacity for neutrophil proteinase inhibition, including those patients with chronic bronchitis, frequent exacerbators or those colonised with bacteria, as recently reviewed. ${ }^{7}$ However, this wealth of data supporting neutrophils in COPD pathogenesis is tempered by two potentially conflicting observations. First, histological studies have not reported a neutrophilia within the airway wall in $\mathrm{COPD}^{8}$ and second, neutrophils are avid phagocytes but COPD patients are still commonly colonised with potentially pathogenic bacteria. ${ }^{9}$ This leads to several key questions. (1) Do neutrophils accumulate in the lungs in COPD? (2) If so, where? (3)

\footnotetext{
${ }^{1}$ Institute of Inflammation and Ageing, University of Birmingham, Birmingham, UK

${ }^{2}$ Respiratory Medicine, University Hospital Birmingham NHS Foundation Trust, Birmingham, UK
}

Correspondence to Dr Elizabeth Sapey, Institute of Inflammation and Ageing, University of Birmingham, Birmingham B15 2TT, UK; e.sapey@bham.ac.uk
Why are they there? (4) Can therapeutics modulate neutrophil accumulation to preserve host health?

The neutrophil is usually considered a transitory rather than tissue resident cell, migrating to areas of inflammation and infection on demand (although recent studies have identified a resident neutrophil in the parenchyma of lymph nodes under basal conditions ${ }^{10}$ ). The dynamics of their journey is mainly unknown and there is still uncertainty whether the recruitment is via the bronchial or pulmonary circulation in humans, or both. Previous studies, in vivo, suggested that the lung contained a physiological, marginated pool of neutrophils, due to the time required to attain the conformational changes needed to allow neutrophils to pass through the narrow pulmonary capillaries, as described in a number of animal models and reviews. ${ }^{11}$ However, careful work using autologous radiolabelled neutrophils and single-photon emission CT over the thorax/upper abdomen at 45 min, 2 hours, 4 hours and 6 hours to determine blood neutrophil clearance from the lung have shed much light on this theory in humans. Initially, Summers et al demonstrated that unprimed neutrophils passed through the lungs with a transit time only a fraction slower than erythrocytes, and with minimal first-pass retention, but that priming (and inflammatory lung conditions, such as Acute Respiratory Distress Syndrome (ARDS)) led to neutrophil retention in the lungs (with the priming agent dictating if retention was likely to be a short-term or longer-term event). ${ }^{12}$ These studies suggested that some of the previous data might reflect neutrophil activation in the hands of the researcher. Then, in vitro, using an optical stretcher and a microcirculation mimetic, the group described how the continued mechanical deformation of primed neutrophils caused active depolarisation (and depriming), ${ }^{13}$ suggesting that the tortuous pulmonary capillary bed might not be a site of cell capture, but instead a vital mechanism to prevent widespread tissue damage caused by an army of activated neutrophils in the circulation.
The current paper $^{14}$ builds on these findings to study the effect of an acute inflammatory challenge in health and in patients with COPD. In the stable state, neutrophil accumulation is increased in COPD patients compared with healthy individuals with little overlap. Furthermore, the process can be modulated (here in healthy controls) using an inhaled lipopolysaccharide (LPS) challenge, simulating an acute infection.

The dynamic retention of neutrophils in the lungs is clearly a feature of COPD and was reproducible in the stable clinical state, enabling this methodology to be used to assess factors that can modulate neutrophil retention to the lung, beneficially or adversely. This study also highlighted the heterogeneity of signal in COPD lungs, which is concordant with the heterogenous burden of pathology throughout the lung, the increased retention of neutrophils in patients with chronic bronchitis (a subgroup that notably experience a higher burden of neutrophilic inflammation) and the reduced signal in areas of large bullae (potentially reflecting the loss of the capillary bed in these areas ${ }^{15}$ ). These studies answered the first question we posed in COPD, neutrophils are clearly being retained in the lungs for longer than in health, and in great numbers.

Currently, these results provide a global lung observation and cannot compartmentalise findings to areas of interest or tissue damage (eg, focusing on the upper zones in areas of emphysema or to the bronchial tree in patients with a chronic bronchitis/colonisation phenotype)-the current methodology cannot answer question 2, the 'where'. The authors describe a weak signal in bullous areas (as expected as there is less tissue); however, combining techniques might provide insight. For example, correcting for lung density may indicate a high signal to mass ratio in these specific emphysematous areas as seen with positron emission tomography (PET) CT scanning, ${ }^{16}$ providing further evidence of the role of the neutrophil in this destructive process. The issue relates to whether the rate of accumulation and the zonal site of accumulation is critical in disease development and pathology. Clearly, the bronchitis phenotype shown here is important in the signal and bronchitis is associated with a more rapid decline in $\mathrm{FEV}_{1}{ }^{17}$ as is the emphysema phenotype. ${ }^{18}$

This methodology cannot, as yet, answer the third question, why neutrophils are retained. The LPS challenge model suggests it is a response to local inflammation induced in health, where the normal lung architecture is preserved. In COPD, 
the chronic inflammatory environment is coupled with tissue damage and remodelling. The damaged capillary networks may be less able to orchestrate neutrophil depolarisation, and thus slow depriming, promoting cells getting 'stuck' in the pulmonary vasculature. However, there is also evidence of neutrophil dysfunction in COPD, displaying increased polarisation associated with phosphoinositol kinase activity, ${ }^{19}$ potentially highlighting neutrophil-dependent mechanisms, which retain the cells in situ.

And so to the final question posed. Can this complex methodology tell us more than cross-sectional data in phase 2 studies, where airway secretion neutrophil count can be shown to respond to anti-inflammatory therapy (eg, in the studies of roflumilast $\left.{ }^{20}\right)$ ? The answer is probably 'Yes'. Cell counts in airway secretions are based on the sampling moment and influenced by dilutional factors in collection and rate of airways clearance, such as expectoration and efferocytosis. The lungs need neutrophils at certain times and physiological recruitment is essential for health, but standard sputum sampling techniques are a blunt tool to assess subtle shifts in the dynamics of neutrophil recruitment and clearance. The strength of the technique described in the current study lies in its ability to monitor uptake dynamically. The methodology would permit tracking of the rate of neutrophil retention against progression, studying patients with a fast decline in $\mathrm{FEV}_{1}$ to potentially develop treatments to normalise neutrophil retention rates. Furthermore, this technique could confirm that any therapy that reduced baseline recruitment to the lungs would still permit increased recruitment when needed, utilising appropriate challenges. This may indeed prove a new dimension to understanding the dynamics of neutrophil recruitment and its modulation in both health and disease.

Its weakness is the intricacy of the measure, using time-consuming methodology with specialised equipment that may limit availability and compliance, especially in more severe disease and during episodes of destabilisation. The studies currently determine neutrophil clearance using an assessment over all the time points of data capture, suggesting the study of one patient would take at least 8 hours. Such studies may need to be focused on patients with 'earlier/ milder' disease who may be better able to manage the time-consuming protocol required. However, given the faster rate of $\mathrm{FEV}_{1}$ decline in this patient group, this may well be where we should be concentrating our best efforts in disease prevention.

Contributors Both authors contributed equally to writing this editorial.

Funding The authors have not declared a specific grant for this research from any funding agency in the public, commercial or not-for-profit sectors.

Competing interests ES reports grants from the Medical Research Council, the Wellcome Trust, the NIHR, the British Lung Foundation and the Alpha 1 Foundation, outside the submitted work. RAS reports grants from the NIHR, the Alpha 1 Foundation, the EU FP-7 and the British Lung Foundation, outside the submitted work.

Patient consent for publication Not required.

Provenance and peer review Commissioned; externally peer reviewed.

\section{(1) OPEN ACCESS}

Open access This is an open access article distributed in accordance with the Creative Commons Attribution Non Commercial (CC BY-NC 4.0) license, which permits others to distribute, remix, adapt, build upon this work non-commercially, and license their derivative works on different terms, provided the original work is properly cited, appropriate credit is given, any changes made indicated, and the use is non-commercial. See: http://creativecommons.org/ licenses/by-nc/4.01.

(c) Author(s) (or their employer(s)) 2019. Re-use permitted under CC BY-NC. No commercial re-use. See rights and permissions. Published by BMJ.

\section{Check for updates}

To cite Sapey E, Stockley RA. Thorax 2019;74:631-632.

Accepted 11 April 2019

Published Online First 16 May 2019

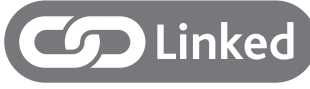

http://dx.doi.org/10.1136/thoraxjnl-2018-212509

Thorax 2019;74:631-632.

doi:10.1136/thoraxinl-2018-213000

\section{REFERENCES}

1 Gill N, Ferreira RBR, Antunes LCM, et al. Neutrophil elastase alters the murine gut microbiota resulting in enhanced Salmonella colonization. PLoS One 2012; 7:e49646

2 Vogt K L, Summers C, Chilvers E, et al. Priming and De-priming of neutrophil responses in vitro and in vivo. 2018.
3 Stone $\mathrm{H}, \mathrm{McNab} G$, Wood AM, et al. Variability of sputum inflammatory mediators in COPD and $\alpha 1$ antitrypsin deficiency. Eur Respir J 2012;40:561-9.

4 Peleman RA, Rytilä PH, Kips JC, et al. The cellular composition of induced sputum in chronic obstructive pulmonary disease. European Respiratory Journal 1999;13.

5 Karlicic V. Cellular composition of bronchoalveolar lavage (BAL) as inflammation indicator in patients with chronic obstructive pulmonary disease (COPD). European Respiratory Journal 2014;44.

6 Donaldson GC, Seemungal TAR, Patel IS, et al. Airway and systemic inflammation and decline in lung function in patients with COPD. Chest 2005;128:1995-2004

7 Walton GM, Sapey E. Neutrophilic Inflammation in the Pathogenesis of Chronic Obstructive Pulmonary Disease AU - Butler, Aidan. COPD: Journal of Chronic Obstructive Pulmonary Disease 2018;15:392-404.

8 O'Shaughnessy TC, Ansari TW, Barnes NC, et al. Inflammation in bronchial biopsies of subjects with chronic bronchitis: inverse relationship of CD8+ T lymphocytes with FEV1. Am J Respir Crit Care Med 1997;155:852-7.

9 Singh R, Mackay AJ, Patel ARC, et al. Inflammatory thresholds and the species-specific effects of colonising bacteria in stable chronic obstructive pulmonary disease. Respiratory Research 2014;15.

10 Bogoslowski A, Butcher EC, Kubes P. Neutrophils recruited through high endothelial venules of the lymph nodes via PNAd intercept disseminating Staphylococcus aureus. Proceedings of the National Academy of Sciences 2018;115:2449-54.

11 Hogg JC. Neutrophil kinetics and lung injury. Physiological Reviews 1987:67:1249-95.

12 Summers C, Singh NR, White JF, et al. Pulmonary retention of primed neutrophils: a novel protective host response, which is impaired in the acute respiratory distress syndrome. Thorax 2014;69:623-9.

13 Ekpenyong AE, Toepfner N, Fiddler C, et al. Mechanical deformation induces depolarization of neutrophils. Science Advances 2017:3:e1602536.

14 Tregay N, Begg M, Cahn A, et al. Use of autologous 99mtechnetium-labelled neutrophils to quantify lung neutrophil clearance in COPD. Thorax 2019;74:659-66.

15 Reid JA, Heard BE. The capillary network of normal and emphysematous human lungs studied by injections of Indian ink. Thorax 1963;18:201-12.

16 Subramanian DR, Jenkins L, Edgar $R$, et al. Assessment of pulmonary neutrophilic inflammation in emphysema by quantitative positron emission tomography. American Journal of Respiratory and Critical Care Medicine 2012;186:1125-32.

17 Stănescu D, Sanna A, Veriter C, et al. Airways obstruction, chronic expectoration, and rapid decline of FEV1 in smokers are associated with increased levels of sputum neutrophils. Thorax 1996;51:267-71.

18 Corsico AG, Grosso A, Albicini F, et al. The Rapid FEV1 Decline in Chronic Obstructive Pulmonary Disease Is Associated with Predominant Emphysema: A Longitudinal Study AU - Cerveri, Isa. COPD: Journal of Chronic Obstructive Pulmonary Disease 2013:10:55-61.

19 Sapey E, Stockley JA, Greenwood H, et al. Behavioral and structural differences in migrating peripheral neutrophils from patients with chronic obstructive pulmonary disease. Am J Respir Crit Care Med 2011;183:1176-86.

20 Grootendorst DC, Gauw SA, Verhoosel RM, et al. Reduction in sputum neutrophil and eosinophil numbers by the PDE4 inhibitor roflumilast in patients with COPD. Thorax 2007;62:1081-7. 